Roth's method it was very difficult, he went on to say, to get dispensary patients to come to the surgeon every day, and he had recently organized an evening school of gymnastics for young girls affected with spinal curvature. Their powers of resistance seemed, as far as he was able to judge, to have developed wonderfully already, and the experiment bade fair to be a very successful one.

In closing the discussion Dr. Ketch said, in reply to Dr. Judson, that he thought any analogy between inflammatory disease of the vertebre and lateral curvature was inadmissible. It seemed to him, also, that Dr. Judson had been especially fortunate in not having met with any of those inveterate cases referred to in the paper and the discussion. He then remarked that there was no deformity so much like that of club-foot as rotary lateral curvature of the spine. The former condition, however, was usually detected soon after birth, and measures were taken to correct it. Hence we met with much fewer cases of inveterate club-foot than of lateral curvature, since the latter was not, as a rule, treated at a sufficiently early stage. After all, the prevention of deformity was the point on which he desired to lay most stress. He believed that no two cases were alike, and whatever the plan of treatment adopted, frequent inspection and the most careful watching were essential on the part of the surgeon.

P. B. P.

\section{LETTER FROM BOSTON.}

(FROM AN OCCASIONAL CORRESPONDENT.

The Murdock Liquid Food Company.

There has been considerable interest in medical circles in this vicinity over a discussion in some of the secular and professional journals about a certain food preparation, manufactured in Boston. Believ. ing that this interest is not confined to the Hub alone, perhaps a few words may be written of interest to those more or less remote from the centre of action. We refer, of course, to the Murdock Liquid Food Company, of which the principal, Mr. Murdock, is the active agent in maintaining for over a year a hospital in the building devoted to the manufacture of their food preparations, the latest of which is "Food Suppositories." This, the "Free Surgical Hospital for Women," is apparently the climax of Mr. Murdock's charity, liberality, and ambition, following his "West End Boys Home" and "Infant Hospital." This building is situated in the newer district bordering on the aristocratic Back Bay of Boston, is easily accessible by horse-cars and occupies a conspicuous corner. It is of brick, several stories high, and, as said above, is devoted to the preparation and putting up of the food, and to the hospital supported from the proceeds of the same. Of the merits of the food as such, we will make no remark, beyond stating that it has been commented upon in a late number of the Boston Journal of Health, and also state that in many of Mr. Murdock's wide-spread advertisements, he claims that under this food many patients recover without the need of any operation. The main entrance is to the office, in the corner of the building, the entrance to that part of the hospital devoted to the regular profession being on the left of this, while that for the Homœopathic hospital is on the right. Over the entrance to the office is a large terracotta representation of the Bulls, colored prints of which are so often seen in apothecary stores. The office is beautifully fitted up, there being oil paintings on the walls, referring mostly to the reputed components of the liquid food, fruits, mutton and beef, and also many pictures representing the different processes of reproducing pictures. One or two paintings lay claim to some old master, and the paintings of the Bulls is here, all pleasing to the eye of the observer. Scattered about are groups of well-known statuary. Adjoining this office is the elegantly equipped office of the journal published by the company, Annals of Gynecology, edited by Dr. E. W. Cushing. This journal is probably well-known to most of the medical profession in the United States, enormous numbers having been circulated of the first three issues, in order that every member of the medical profession in the country might become acquainted with it.

Just here we will say, that many modern conveniences are found in this building, electric locks guarding the doors, electric clocks telling the time, and the building is lighted by electricity, has an elevator, and in fact is a well equipped building. In the basement is a large engine to furnish power for the system of indirect heating that Mr. Murdock has inaugurated: the air comes from the roof, by means of fans to chambers heated by steam pipes, whence it is delivered to the different rooms at a proper temperature, within a few seconds. The second floor of the building is devoted to the manufacture, (for account see February, 1888, number of Boston Journal of Health,) bottling and storage of the preparations, while the third floor is devoted to the Hospital and its appurtenances. The Hospital is in reality two, they being entirely distinct and separate, each having its own entrance from the street for patients and visitors, and each having its own staff made up of gentlemen of the Regular profession on the one side, and of the Homoopathic belief on the other. Each has its own operating room, small and large wards, etherizing room, waiting rooms and necessary sanitary arrangements of a hospital. One of the wards on the regular side is called the Fabiola Ward in memory of founder of some Roman Hospital. The convalescent patients of both sides eat at the same table, one kitchen doing the cooking for both. In the regular side are special wards for septicremic and cancer cases, and also a well equipped laboratory for such bacteriological and pathological work as may be of interest to surgical gynecological work. The combined hospital will accommodate about 150 patients. Dr. E. W. Cushing has charge of the regular side, and Dr. Packard of the Homœopathic. It was in this hospital that Dr. Martin, of Berlin, operated while in Boston, performing his operation of removal of the uterus through the vagina. Each patient is required to take a certain quantity 
of the food at each meal, before and after treatment, and, as was previously mentioned, some have recovered on this alone, and a list of the number of operatiuns may be seen in almost every newspaper published in Boston.

A few words in regard to the discussion: As has been said, the Hospital has been under operation for over a year, and as Mr. Murdock states in his advertisements, one side is under the management of gentlemen belonging to the Massachusetts Medical Society, these gentlemen being connected with it from the start. The whole thing has been looked upon as not exactly the proper thing; still, nothing was done, and things simply took their own proper course, till the Boston Journal of Health, in a series of articles exposing fraudulent and deceptive foods and medicines, took up "Murdock's Liquid Food" among the number, exposing the falsity of the preparation, composition, and profit in a lengthy article. Mr. Murdock then saw fit to answer this, stating why he thought the article had been written, and denying some of the statements, making quite a breezy article: To this the Journal replies only in stronger terms, denouncing in emphatic language the preparation, and replying to some of Mr. Murdock's statements or rather mis-statements; things were getting interesting.

In the meantime Dr. Marcy, who had severed his connection some time previously to any thought of the discussion, published in the Boston Medical and Surgical Journal, a card stating his previous withdrawal from the Murdock Hospital, and giving as his reasons for so doing that the hospital was not acting up to its agreement, in regard to running and management of the hospital. Immediately, Mr. Murdock replies in the following number of the same journal, contradicting flatly some of Dr. Marcy's statements, and referring to letters of the Council of Ethics of Massachusetts Medical Society, in commendation of the enterprise, which in the next issue of the Journal, was flatly contradicted by the Council, thus leaving the way open for Dr. Cushing to show the letter which they claim he has not.

Here the matter rested, and interest is still maintained as to the outcome. Mr. Murdock has very much retracted and modified his advertisement in the daily papers, but probably with the means at his disposal, among which may be reckoned the Annals of Gynecology and the hospital, will endeavor to keep before the public the merits of his food preparations, while the Journal of Health intends pushing its exposé, and bring the whole thing plainly and truthfully in its proper light, along with others, the latest being Scotch Oats Essence.

I hope we have not wearied you with this account of our little tempest in our medical teapot, which has been written only with the idea that some of the wrath and fury of the storm may have bubbled over, and reached the outside world, thus concerning, perhaps, others than the ones directly interested.

w.

DR. OLIVER WENDElt Holmes has presented his medical library to the Boston Medical Library Association.

\section{INVERSION FOR SUSPENDED ANIMATION IN} AN ESTHESIA.

Dear Sir:-In The Journal of April 7 th, is an editorial on the recent paper of Dr. J. J. Chisolm, entitled, "A very valuable lesson for those who use anæsthetics." It is customary, I think, for a writer or a reviewer in papers like those just mentioned to allude to the published observations of others who have experimented in the same field. I have not a copy of Dr. Chisolm's article and do not know what reference is made to other observers. The general reader would, however, infer from the editorial that what had been written previously had escaped the attention of the author and of the editor.

The subject of position is cases of apparent death from the use of chloroform is of great importance. After repeated experiments in cases of slight and alarming symptoms during the administration of chloroform, I became convinced that a sure remedy was at hand in every such case. If death has occurred, there is reason to believe that there was carelessness in watching for the first cessation of breathing and of the heart's action, and that there was an attempt to use other means previous to the complete inversion of the patient.

As an interne in the Massachusetts General Hospital I once aided a distinguished surgeon in holding suspended by one foot, a boy with a crushed thigh, who was, as it were, dead. He was held in this position till life reappeared. My own observations and experiments were made in $1867-8$, and were published in the Transactions of the Illinois State Medical Society for the year 1868 . Portions of this paper were copied in the work of Prof. H. M. Lyman on "Artificial Anæsthesia," etc. The story of Piorry, Nélaton and the rats was entirely unknown to me at the time I made my report. The late Dr. J. Marion Sims, and a physician in New Orleans, whose name I have forgotten, published articles on this subject some years since.

Chicago, April 16, 1888 .

[The limits of editorial space precluded the publication of the names of men that have used inversion in the cases under consideration, and their experiments. The writer of the editorial article in question knew that inversion has been used by other men than Dr. Chisoim, and he himself has used it successfully in two cases in which he was the administrator. Obviously, also, it is impossible for a writer to search such inaccessible literature as State Society Transactions for possibly existing papers. The editorial was not written to tell something actually $n \in w$, but to call attention to a method that has given good results in the hands of a surgeon of vast experience.-ED.]

\section{RUPTURE OF FUNIS.}

Dear Sir:-On April $4^{\text {th }}$ I was called to see Martha Brown (col'd), who had given birth to ten children. She had been in labor for about fortyeight hours. The head had been born about four hours before I saw her, and with the uterus most powerfully contracting failed to make any further 